\title{
CONCEPÇÃO DE BIOSSEGURANÇA DE DOCENTES DO ENSINO TÉCNICO DE ENFERMAGEM EM UM ESTADO DO SUL DO BRASIL
}

\author{
CONCEPT OF BIOSAFETY AMONG TECHNICAL NURSING EDUCATION TEACHERS IN A STATE \\ IN SOUTHERN BRAZIL
}

\author{
CONCEPCIÓN DE BIOSEGURIDAD DE DOCENTES DE LA ENSEÑANZA TÉCNICA DE ENFERMERÍA \\ EN UN ESTADO DEL SUR DE BRASIL
}

\author{
Gerusa Ribeiro ${ }^{1}$ \\ Denise Elvira Pires de Pires ${ }^{2}$ \\ Rita de Cássia Flôr ${ }^{3}$
}

Resumo O respeito a normas de biossegurança é fundamental para a realização de cuidados seguros, e o ensino na formação profissional em saúde desempenha papel fundamental nesse processo. Este artigo é resultado de pesquisa exploratório-descritiva, de abordagem qualitativa, com o objetivo de identificar as concepções de biossegurança de docentes do ensino técnico de enfermagem que atuam em instituições vinculadas à Rede Federal de Educação Profissional e Tecnológica de um estado do Sul do Brasil. Os dados foram coletados por meio de entrevistas com o universo dos enfermeiros docentes de duas instituições envolvidos em atividades supervisionadas de estágio durante o período de um mês, em 2012. Os resultados mostraram três visões de biossegurança: como sinônimo de equipamentos de proteção individual; como proteção dos envolvidos no trabalho; e como segurança da vida. Identificou-se, ainda, que o docente reproduz o que aprendeu na escola e toma decisões influenciado pelos cenários de sua prática. Concluiu-se que os docentes entendem a importância de adotar práticas laborais seguras e que o ensino influencia nas ações dos futuros profissionais; no entanto, a concepção de defesa da vida foi minoritária.

Palavras-chave exposição a agentes biológicos; biossegurança; enfermagem; educação técnica em enfermagem; saúde do trabalhador.
Abstract Respect for biosafety standards is critical for the provision of safe care, and education in vocational training in health plays a key role in this process. This article is the outcome of an exploratory-descriptive research project that used a qualitative approach to identify how technical education nursing teachers working at institutions linked to the Federal Professional and Technological Education Network in a state in Southern Brazil conceive biosafety. Data were collected through interviews conducted for a one-month period, in 2012, among nursing teachers of two institutions involved in supervised internship activities. The results showed three views on biosafety: as a synonym of personal protective equipment; as protection of those involved in the work; and as safety for life. It was also noted that teachers reproduce what they learned in school and make decisions influenced by scenarios in their practice. It was concluded that teachers understand the importance of adopting safe working practices and that education influences the actions of future professionals; however, a minority of them took the concept of defending life involved in this issue into account.

Keywords exposure to biological agents; biosafety; nursing; technical education in nursing; worker's health. 


\section{Introdução}

O ensino da enfermagem envolve a articulação de teoria e capacitação prática, fundamentadas no conhecimento científico e na legislação profissional e educacional, visando à formação de profissionais sensíveis e com competência técnica para prestar cuidados seguros para si e para os usuários do serviço de saúde (Brasil, 2005a).

A legislação do exercício profissional de enfermagem vigente no Brasil, por meio das leis n.os 7.498/1986 (Brasil, 1986) e 2.604/1955 (Brasil, 1955), confere ao enfermeiro a responsabilidade pela formação dos profissionais. Nesse cenário, podem exercer a enfermagem os enfermeiros, técnicos de enfermagem (TEs), auxiliares de enfermagem (AEs) e parteiras. Destaca-se que desde 1980, principalmente com a aprovação da lei n. 7.498/1986 (Brasil, 1986) e da Lei de Diretrizes e Bases da Educação Nacional (LDB), de n. 9.394/1996 (Brasil, 1996), o número de TEs tem crescido significativamente no Brasil, passando de 6,6\% em 1983 (Pires, Lorenzetti e Gelbcke), 2010) para 40\% em 2012 (Krempel, 2012). Nos estados do extremo sul do Brasil, em 2012, os TEs representavam 60,8\% em Santa Catarina (Coren-SC, 2014) e 64,5\% no Rio Grande do Sul (Coren-RS, 2014). Esses dados mostram a importância dos TEs na composição da força de trabalho desse núcleo profissional e a necessidade de se estudarem os diversos aspectos envolvidos na sua formação.

Para o desenvolvimento de práticas seguras em saúde, é fundamental a aplicação das normas relativas à biossegurança. A expressão biossegurança surgiu nos anos 1970 nos Estados Unidos, com o advento da biotecnologia e a necessidade de formular normas para a segurança no trabalho em laboratórios onde ocorria manipulação de material genético. O termo foi cunhado em 1975, em encontro ocorrido no Centro de Convenções de Asilomar, na Califórnia, em face do reconhecimento dos riscos para trabalhadores, sociedade e meio ambiente e da necessidade de formulação de regras protetoras. Na década de 1980, surgem os primeiros manuais de biossegurança. Dentre essas publicações, destaca-se o primeiro manual de biossegurança editado em 1984 pelo Centers for Disease Control and Prevention (CDC), nos Estados Unidos, fazendo referência à terminologia biosafety: biossegurança (Oda e Santos, 2012).

Com as formulações acerca da biossegurança, a ideia de segurança do trabalho em laboratórios que manipulam material genético foi ampliada, incluindo a preocupação com os impactos dessas práticas sobre o meio ambiente e a saúde humana (Costa e Costa, 2003). A literatura registra, ainda, concepções de biossegurança que vão além da formulação de regras para a proteção dos trabalhadores expostos a agentes biológicos e manipulação genética. A visão ampliada engloba a preservação da saúde pública e do 
meio ambiente, no sentido de segurança da vida (biosafety), e tem interface com diversas áreas, como a legislação trabalhista e sanitária, a engenharia, a agricultura, a química e a exobiologia (Wong, 2009; Brasil, 2003, 2005a; Cardoso et al., 2005).

No Brasil, a lei n. 8.974 (Brasil, 1995), aprovada em janeiro de 1995, criou a Comissão Técnica Nacional de Biossegurança no, à época, Ministério da Ciência e Tecnologia (CTNBio/MCT), tendo sido revogada pela lei n. 11.105, de 24 de março de 2005 (Brasil, 2005a). No âmbito do Ministério da Saúde, foi criada a Comissão de Biossegurança em Saúde (CBS), por meio da portaria n. 343/GM, de 19 de fevereiro de 2002 (Brasil, 2002), substituída pela portaria GM/MS n. 1.683, de agosto de 2003 (Brasil, 2003). Em 2005, o Ministério do Trabalho e Emprego criou a norma regulamentadora n. 32 (NR 32), que estabelece normas relativas à segurança e à saúde no trabalho em serviços de saúde (Brasil, 2005c). A NR 32 trata das medidas de proteção à exposição aos riscos biológicos, além de outras medidas de proteção à saúde dos trabalhadores que atuam em serviços de saúde (Coren-SC, 2011; Brasil, 2003, 2005a, 2005c).

É importante destacar que a NR 32 remete a outras normas regulamentadoras, assim como às resoluções da Agência Nacional de Vigilância Sanitária (Anvisa), da Comissão Nacional de Energia Nuclear (CNEN), da Associação Brasileira de Normas Técnicas (ABNT), do Instituto Nacional de Metrologia, Qualidade e Tecnologia (Inmetro) e dos ministérios da Saúde e do Meio Ambiente (Teixeira e Valle, 2010). A NR 32 reconhece o risco biológico aos quais os trabalhadores do setor saúde estão expostos, dentre outros riscos. Prevê a instituição de um ambiente seguro com disponibilidade de equipamentos de proteção, assim como a educação dos sujeitos para condutas laborais protetoras (Coren-SC, 2011; Brasil, 2005c).

No que diz respeito às medidas de prevenção e proteção, faz-se necessário o uso de barreiras que possam minimizar ou prevenir a exposição aos riscos ocupacionais, o que se denomina de equipamentos de proteção individual (EPIs) e de proteção coletiva (EPCs) (Teixeira e Valle, 2010).

Os EPIs, conforme recomendação da NR 32, são equipamentos do tipo descartáveis ou não, que devem estar nos locais de trabalho em número suficiente e à disposição dos trabalhadores e ser repostos sempre que necessário. Os EPIs são regulamentados pela NR 6, do Ministério do Trabalho e Emprego, publicada em 8 de junho de 1978 (Brasil, 1978). Desde sua publicação, esta NR passou por algumas alterações e atualizações. A última alteração foi feita Secretaria de Inspeção do Trabalho (SIT), por meio da pela portaria n. 194, de 7 de dezembro de 2010 (Brasil, 2010). O EPI é inserido no ambiente de trabalho de acordo com o tipo de material infeccioso e a atividade desenvolvida. Comumente são usados a máscara, as luvas, os óculos de proteção e o avental (Coren-SC, 2011; Brasil, 1978, 2010; Teixeira e Valle, 2010). 
Os EPCs são disponibilizados para o uso do conjunto dos trabalhadores envolvidos em determinada área de trabalho, para evitar danos e para intervenções em situações de emergência. Nessa categoria, são citados, dentre outros, cabines de segurança biológica e química, chuveiros de emergência, lava-olhos e equipamentos de combate a incêndios. Estes equipamentos, além de disponíveis, devem estar em boas condições de uso. Os profissionais necessitam de conhecimentos em biossegurança e de boas práticas laborais para que possam melhor utilizar e selecionar o equipamento adequado, garantindo assim a sua proteção e a da equipe, dos usuários e do meio ambiente (Teixeira e Valle, 2010).

O enfermeiro é o profissional que tem a responsabilidade técnica pelo trabalho desenvolvido pela equipe de enfermagem nas dimensões cuidar, educar/pesquisar e gerenciar (Pires, 2009). Nesse sentido, a formação de novos profissionais, tanto de nível superior quanto de nível médio, é fortemente influenciada pelo conhecimento técnico e político dos enfermeiros. Essa formação também requer a vivência, pelos educandos, de situações reais de trabalho nas quais se expressam relações, posturas e aplicação de conhecimentos, inclusive sobre biossegurança. Além dos espaços de ensino teórico, há o enfrentamento de situações concretas de trabalho, hospitalares e extra-hospitalares, nas quais se expressam conhecimentos e práticas extremamente significativas para a formação dos novos profissionais. A íntima relação entre teoria e prática é especialmente importante na enfermagem e requer conhecimentos de base científica e habilidade para ação, além do pensar crítico sobre o fazer.

Os conhecimentos acerca de normas, procedimentos e condutas biosseguras deveriam propiciar uma visão ampla, integrada e interdisciplinar da biossegurança, visando minimizar riscos de cuidadores e dos usuários, assim como do meio ambiente e da sociedade. Essa visão ultrapassa a abordagem restrita de treinamento, aquisição de destreza e imposição de normas (Pereira, 2009).

Na formação em enfermagem e nas demais profissões da saúde, estudos têm demonstrado a pouca ênfase no ensino da biossegurança. A temática não consta das diretrizes curriculares (Brasil, 2005b), e quando compõe os conteúdos curriculares, estes se apresentam de forma bastante genérica e pontual durante o desenvolvimento do curso. Praticamente inexiste uma integração transversal nos currículos dos cursos (Silva e Mastroeni, 2009; Andrade e Sanna, 2007). Trata-se de um tema urgente e fundamental para a formação de uma cultura educacional prevencionista, com consequente impacto positivo na prática (Costa e Costa, 2010).

O presente estudo foi motivado pelo reconhecimento da importância da realização de práticas seguras para profissionais e usuários dos serviços de saúde; dos técnicos de enfermagem como um grande contingente na 
composição da força de trabalho de enfermagem no Brasil; e da relevância do ensino na formação de profissionais competentes para o exercício de práticas seguras. Nesse sentido, formulou-se a seguinte questão de pesquisa: O que os docentes do ensino técnico de enfermagem entendem sobre biossegurança? O estudo teve então, como objetivo, identificar as concepções de biossegurança de docentes do ensino técnico de enfermagem de duas instituições que integram a Rede Federal de Educação Profissional e Tecnológica de um estado do Sul do Brasil.

\section{Entrevista com docentes sobre a biossegurança e a aplicação na prática da supervisão de estágio em Enfermagem}

A pesquisa ${ }^{4}$ que deu origem a este artigo tratava-se de um estudo exploratório e descritivo de abordagem qualitativa, desenvolvida em duas instituições do ensino técnico profissionalizante que compõem a Rede Federal de Educação Profissional e Tecnológica em um estado da região Sul do Brasil. Os institutos federais são instituições educacionais públicas que compõem essa rede e estão vinculados ao Ministério da Educação por meio da Secretaria de Educação Profissional e Tecnológica (Setec). Tais institutos atuam em todos os níveis e modalidades de ensino, especializados na oferta de educação profissional e tecnológica. Nas suas ações, têm como finalidade a justiça social, a equidade, a competitividade econômica e a geração de novas tecnologias, com capacidade e competência para retribuir de forma rápida e dinâmica as demandas pela formação profissional (Brasil, 2008).

A escolha do local e dos participantes do estudo articulou os critérios de conveniência e intencionalidade. O critério de conveniência foi utilizado pela facilidade de acesso das pesquisadoras à Rede Federal de Educação do estado. Inicialmente, pretendia-se incluir escolas públicas e privadas e circunscrever a pesquisa a uma regional do estado. Em face das dificuldades de autorização pelas escolas privadas, decidiu-se por realizar o estudo no total de instituições da rede que ofertam o curso de formação de técnicos de enfermagem - Campus 1 e Campus 2, um em cada município. O critério de intencionalidade foi utilizado para a escolha dos sujeitos, incluindo todos os docentes enfermeiros dos cursos técnicos profissionalizantes das duas instituições que estivessem realizando atividade prática supervisionada no período da coleta dos dados, outubro de 2012. Todos aceitaram participar da pesquisa. Foram excluídos os professores que não estavam em atividades práticas.

O número de participantes totalizou 11 enfermeiros docentes que estavam em atividade prática no momento da pesquisa: oito do Campus 1 (30\% do total) e três do Campus 2 (90\% do total). 
Para a coleta dos dados, empregou-se a técnica de entrevista com questionamentos acerca do entendimento dos docentes sobre a biossegurança, do conhecimento das normas e legislação relativas à biossegurança e da relação entre as normas legais e as possibilidades de sua aplicação na prática da supervisão de estágio. Os docentes foram previamente contatados e as entrevistas agendadas conforme disponibilidade, sendo realizadas nos locais de práticas: hospitais (seis), unidades de pronto atendimento/pronto atendimento (UPA/PA) (três), unidades básicas de saúde (UBS) (uma) e centro de atenção psicossocial (CAP) (uma).

As entrevistas foram gravadas e transcritas pela primeira autora, e a análise dos dados orientada pela análise temática de conteúdo de Bardin (2010). A organização dos dados obedeceu a três fases cronológicas: pré-análise, exploração do material e tratamento dos resultados. Na primeira se realizou, inicialmente, a leitura de cada entrevista a fim de se apropriar dos textos e apreender as formulações e os entendimentos de cada entrevistado; a segunda foi a fase mais longa e fastidiosa, que consistiu na elaboração das codificações e na formulação das categorias; e a terceira e última fase permitiu articular as expressões dos participantes relativas a cada categoria de modo a possibilitar a visualização dos resultados da pesquisa.

Todos os preceitos éticos relativos à pesquisa com seres humanos foram respeitados, incluindo a leitura e a assinatura do termo de consentimento livre e esclarecido, além do respeito ao direito de se recusar a participar da pesquisa e da possibilidade de desistência a qualquer momento. Com o objetivo de garantir o sigilo e o anonimato, as falas utilizadas no manuscrito foram identificadas pela letra E, seguida do número de ordem cronológica de realização das entrevistas. A pesquisa foi aprovada pelo Comitê de Ética em Pesquisa da Universidade Federal de Santa Catarina (UFSC), de acordo com o protocolo n. $4.410 / 2012$.

\section{A biossegurança na concepção do docente em Enfermagem}

Do conjunto das entrevistas, emergiram três concepções representativas do entendimento de biossegurança por parte dos docentes. A primeira, mais restrita, entende biossegurança como sinônimo de EPI; a segunda a relaciona a medidas mais amplas de proteção, incluindo EPI, EPC e promoção de ambiente seguro para trabalhadores, equipes e usuários; a terceira entende a biossegurança como segurança da vida. Identificou-se, ainda, que a prática pedagógica expressa o conhecimento do docente e as relações interpessoais, assim como as possibilidades e os constrangimentos para a realização de ações seguras. 


\section{Biossegurança como EPIs}

Os EPIs são instrumentos de trabalho que variam conforme a necessidade em diferentes ambientes de atuação. São instrumentos produzidos para serem utilizados visando reduzir, ao mínimo, a exposição de trabalhadores e ambiente a riscos decorrentes das atividades de trabalho. Predominantemente, os EPIs são percebidos como protetores da exposição aos agentes biológicos, mas dizem respeito também a exposições de outra natureza como, por exemplo, química e ionizante. Tais equipamentos são entendidos como uma barreira primária, colocada entre os trabalhadores e os materiais perigosos. Dentre os EPIs, pode-se citar: jalecos de manga longa, uniforme com calça e blusa de manga longa, calçados fechados, luvas e óculos de proteção, máscaras, protetor auditivo e facial (Custódio e Santos, 2013; Souza et al., 2014; Brasil, 2005c; Centers for Disease Control and Prevention, 2009; Siegel, Rhinehart e Chiarello, 2007).

Parte dos docentes entrevistados $(36,4 \%)$ entende biossegurança como sinônimo de EPI, como se destaca nas falas a seguir:

(...) biossegurança, ela é fundamental na nossa profissão, eu estou colocando como biossegurança o EPI, que são os equipamentos (El).

A biossegurança sempre está mais relacionada ao que o aluno ou profissional utiliza para sua segurança, na utilização da luva, de máscara, de avental, de óculos na hora da aspiração (E7).

Biossegurança seria no caso o uso do EPI corretamente, dentro do hospital, para eles estarem utilizando o EPI e lavarem as mãos corretamente (E2).

Para os entrevistados, biossegurança diz respeito ao uso de equipamentos de proteção, visando minimizar a exposição a agentes infecciosos e evitar acidentes e adoecimento, decorrentes de suas atividades de trabalho.

A relação entre trabalho e saúde é reconhecida na literatura desde a emergência do modo capitalista de produção e dos estudos sobre a situação da classe trabalhadora, em especial na Inglaterra nos séculos XVIII e XIX (Marx, 1989). No entanto, é bem mais recente a inclusão dos ambientes de cuidado em saúde como produtores de adoecimento. No Brasil, o marco desse reconhecimento institucional foi a publicação da norma regulamentadora 32 (NR 32) do Ministério do Trabalho e Emprego, em 2005 (Brasil, 2005c).

No campo da saúde dos trabalhadores, a preocupação com o uso de equipamentos de proteção é histórica. Desde o período romano, registra-se 
o uso de máscaras confeccionadas com bexigas de animais, que eram usadas para proteção das vias aéreas (Teixeira e Valle, 2010).

\section{Biossegurança como proteção dos envolvidos no trabalho}

Nesta categoria, identificou-se o entendimento da biossegurança como autoproteção, proteção dos estudantes, dos usuários, da equipe de enfermagem e de saúde, assim como para a adoção de medidas para garantir a segurança dos ambientes de trabalho. Esta visão foi majoritária, sendo percebida por $45,5 \%$ dos docentes entrevistados.

São todas as formas de a gente se proteger, orientações para os alunos em relação à proteção individual e do paciente; todas as formas desde materiais, objetos, como eles devem se portar para não acontecer nenhum acidente, com o aluno, profissional, o professor e com o paciente (E3).

Biossegurança é o conjunto de práticas adotadas pelos profissionais que lidam com o risco biológico para proteção individual. (...) conjunto de práticas, uso do EPI (...) que não exponha desnecessariamente ao risco, a organização do ambiente, orientação da equipe, orientação de todos aqueles que lidam com esse tipo de materiais (E6).

(...) a biossegurança (...) não é só uma lavagem de mãos, é tudo o que está envolvido (...) o EPI é importante na biossegurança, mas vamos ver, as pessoas pensam muito só na luva, mas a luva para me cuidar, não para cuidar da segurança do paciente (...) para cuidar tanto da segurança do local quanto dos profissionais e do paciente que está ali naquele momento (E10).

É tudo aquilo que engloba a proteção tanto do trabalhador da saúde quanto das pessoas que a gente atende, então, ali engloba tudo, todos os procedimentos que serão executados se eu estou usando da biossegurança, se eu estou seguindo aquelas normas de biossegurança que são preconizadas (E8).

Ausência ou uso inadequado dos EPIs, déficit nos EPCs e ambientes inadequados expõem os trabalhadores das instituições assistenciais, alunos e docentes a agentes infecciosos e a riscos de acidentes e adoecimento. Os docentes entrevistados percebem a relação entre trabalhar na área da saúde e a possibilidade de adoecer. Demonstram familiaridade com o termo biossegurança, associando-o à importância do uso de EPIs, e reconhecem a importância do ensino e da adoção de medidas que minimizem a exposição a agentes infecciosos e a acidentes nos ambientes de trabalho e de ensino 
prático. Para isso, mencionam sua preocupação com o uso correto dos EPIs e com a execução de técnicas seguras, correspondendo ao registrado por Souza e colaboradores (2008) quanto ao reconhecimento da necessidade de disponibilização e uso correto de EPIs e EPCs.

Os docentes relatam ainda sua percepção da biossegurança como relacionada ao bem-estar dos profissionais, dos alunos e dos doentes.

Biossegurança, para mim, no meu trabalho é essencial tanto para o bem-estar do meu aluno quanto para o meu também e o do paciente. Além disso, tem a questão dos colegas de trabalho também. Quando eu não me importo, coloco meu colega também em risco (E5).

A enfermagem manuseia, constantemente, materiais perfurocortantes. Expõe-se a fluidos corporais, a resíduos infectantes, assim como está sujeita a um ambiente físico às vezes inadequado, com falta de EPIs, EPCs e demais instrumentos de trabalho. Tal cenário é compartilhado por docentes e alunos/estagiários, que dividem esses espaços no processo de aquisição de conhecimentos. A conduta do docente facilita ou dificulta o ensino e a aprendizagem no tocante à prevenção, contribuindo ou não para o bem-estar dos envolvidos.

Ensinar na enfermagem envolve, necessariamente, teoria e prática, e "é durante a prática que os alunos se deparam com situações que exigem a utilização destes equipamentos de segurança” (Souza et al., 2008, p. 430). Ao realizar as atividades práticas, no processo de ensinar e refletir sobre como fazer, o docente confronta seu conhecimento sobre biossegurança com as prescrições legais e institucionais, com seus valores e com a realidade dos ambientes assistenciais. É nesse cenário complexo que o docente toma decisões a respeito do 'que fazer' e de 'como fazer'. O meio é sempre infiel e envolve, permanentemente, julgamentos e tomada de decisões, como mencionado por Schwartz e Durrive (2010).

\section{Biossegurança como segurança da vida}

A terceira categoria, mencionada por $18,2 \%$ dos entrevistados, foi o entendimento de biossegurança como segurança da vida, ou seja, o conjunto de medidas para o viver livre de riscos

Biossegurança, como o nome próprio diz, bio - vida, segurança (...) tudo o que se relaciona às pessoas, animais e que tem vida. (...) principalmente nas questões da segurança da saúde do trabalhador, nos aspectos físicos, químicos, biológicos, mas tem também aqueles estudos do DNA (...) células-tronco, tudo o que está relacionado à segurança da vida (E11). 
Biossegurança é o cuidado que a gente tem que ter com a vida, a segurança da vida; então, trazendo para nossa área, professor da área da enfermagem, a segurança de nós, docentes, e a segurança da vida do nosso estagiário e do futuro técnico de enfermagem (E4).

A literatura é ambígua em relação ao conceito de biossegurança. Tanto se encontra a sua compreensão como um conjunto de medidas para minimizar o risco biológico quanto o entendimento do sentido etimológico da palavra biosafety como segurança da vida. O prefixo bio vem do grego e significa vida; já o sufixo safety significa segurança, a "qualidade de ser seguro, livre de dano" (Costa, 2005, p. 24).

$\mathrm{O}$ docente parece relacionar biossegurança à atividade que identifica o fazer profissional da enfermagem - o cuidado das pessoas, no sentido de bem-estar, felicidade, defesa da vida. Como docentes de cursos técnicos de enfermagem, seu objeto de trabalho são os alunos, e na atividade prática supervisionada seu olhar se volta para eles em sua integralidade, considerando que o ensinar ultrapassa uma visão de capacitação instrumental técnica. A defesa da vida é um princípio defendido por Campos (1997, p. 242) como orientador do fazer dos profissionais de saúde: “a ética dos profissionais de saúde não poderia estar fundada em outro princípio que não fosse o de defesa da vida".

Teixeira e Valle também empregam a terminologia biossegurança em sentido mais amplo do que o usualmente aplicado nas instituições de saúde ou ambientes laboratoriais.

A biossegurança é o conjunto de ações voltadas para a prevenção, minimização ou eliminação de riscos inerentes às atividades de pesquisa, produção, ensino, desenvolvimento tecnológico e prestação de serviços, riscos que podem comprometer a saúde do homem, dos animais, do meio ambiente ou a qualidade dos trabalhos desenvolvidos (Teixeira e Valle, 2010, p. 19).

A relação entre o docente e o aluno durante a atividade prática supervisionada se dá em cenários às vezes não tão habituais para o aluno e com os quais o docente nem sempre está familiarizado. O desenvolvimento de atividades práticas é um terreno de incertezas a ser gerenciado por docentes e discentes, o que também foi registrado por outros pesquisadores como Canalli, Moriya e Hayashida, quando afirmam:

percebe-se que os docentes têm papel fundamental na prevenção de acidentes com material biológico e deveriam minimizar o estresse em campo de ensino prático, tornando o aluno mais seguro e atento na realização de atividades (Canalli, Moriya e Hayashida, 2011, p. 104). 


\section{O docente reproduz o que aprendeu na escola e gerencia a atividade de educar em cenários complexos e singulares}

Ao abordar o tema biossegurança no âmbito acadêmico, o docente reproduz o conhecimento que recebeu durante a sua formação, quer seja na graduação, quer em cursos de pós-graduação. Na dinâmica da sala de aula, nos laboratórios de ensino e nos ambientes de cuidado, ocorre um debate permanente de valores e de tomada de decisões em face das possibilidades e dificuldades expressas nos diferentes cenários de prática e nos diferentes grupos de educadores e educandos.

Utilização dos EPIs conforme a gente vai fazendo as atividades (...) a gente usa o conhecimento que a gente tem e procura sempre pôr em prática; não fazer nenhuma atividade que possa colocar em risco (...) (E11).

O aluno acaba pegando aquilo para ele também. Como eu trago dos meus professores, acabo transmitindo isso para meus alunos também (...). Se eu não tenho conduta correta dentro daquele ambiente, acabo colocando em risco a mim, os pacientes, os colegas, os meus alunos. Isso é uma coisa que sempre me vem à mente. Assim, quando se fala em biossegurança, esse é o cuidado que eu tenho: manter íntegras as pessoas que estão a minha volta e a mim também, dentro daquele ambiente que é o ambiente hospitalar (E5).

A gente tem essa preocupação de passar aos alunos de fazer o uso da biossegurança na prática profissional, o EPI, o uso de luvas, principalmente em procedimentos que, algumas vezes, a gente presencia que no cotidiano não são usados em alguns procedimentos, mas que têm sua importância (E8).

No mesmo sentido desses depoimentos, uma pesquisa feita com docentes e alunos de cursos técnicos da saúde de nível médio verificou que a percepção deles sobre biossegurança relaciona-se, em primeiro lugar, ao reconhecimento de que existem agentes de risco e, em segundo, que os EPIs são necessários. Os autores constatam que essas percepções sobre biossegurança ainda estão muito centradas em normatizações e na prevenção dos riscos físicos, químicos, biológicos, ergonômicos e psicossociais, demonstrando fragilidades no seu ensino (Costa e Costa, 2010). Em outra publicação, sugerem-se mudanças nas práticas educativas e conceituais inserindo-se a ideia de "estado de biossegurança", ou seja, "harmonia entre o homem, os processos de trabalho, a instituição e a sociedade", visando ampliar a visão do fenômeno (Costa, 1998, p. 33).

É no processo de ensino-aprendizagem que conhecimentos fundamentados e atualizados sobre a importância e o uso correto do EPI são abordados, e 
é nessa construção que se sensibiliza e se constituem atitudes profissionais seguras, com conhecimentos e habilidades (Souza et al., 2008). Considerar o enfermeiro educador comprometido com a formação e habilitado para educar/ensinar é essencial para torná-lo um profissional de referência no processo de cuidar em saúde e provedor do aprendizado significativo (Waldow, 2009).

Cabe registrar que, nesta pesquisa, o entendimento de biossegurança mencionado pelos docentes não incluiu nenhuma referência à ética e à segurança do meio ambiente e da vida em sociedade no que diz respeito aos resíduos produzidos pelos serviços de saúde. Segundo Pereira e colaboradores (2009, p. 301), biossegurança deve envolver uma reflexão que ultrapasse "a ideia da simples normatização, e abranger, inclusive, aspectos relativos à ética, já que ela está implícita em praticamente todas as ações da biossegurança".

O tema é relevante e está incluído na Agenda Nacional de Prioridades de Pesquisa em Saúde. Em 2009, na Oficina de Biossegurança em Saúde, ocorreram debates sobre ele no Sistema Único de Saúde. Dos itens tratados, destaca-se a necessidade de disseminação do conhecimento sobre normas e legislações, além de monitoramento das atividades laboratoriais e de controle e risco da saúde humana e ambiental. O debate mostrou ainda a carência de profissionais qualificados para implantar projetos de biossegurança na área da saúde em diferentes regiões do Brasil (Custódio e Santos, 2013).

É notória a variedade de ações e atividades que requerem dos docentes em enfermagem criatividade, flexibilização e improviso. Nas condutas biosseguras dos espaços de assistência de saúde ou nas instituições de ensino, esses profissionais devem manter organização e planejamento, desenvolvendo um ambiente de ensino e aprendizagem constante voltado para promover uma cultura de prevenção aos riscos. É possível que a postura biossegura possa ser sensibilizada ainda no ensino, por meios dos espaços, equipamentos e qualidade dos recursos físicos e também humanos.

\section{Considerações finais}

Conclui-se que o entendimento dos docentes do ensino técnico de enfermagem das instituições estudadas acerca da biossegurança é associado, fortemente, à utilização de EPI. Também se identificou o sentido de proteção de todos os envolvidos no trabalho e de defesa da vida. No entanto, a dimensão ética de práticas biosseguras e a relação entre resíduos hospitalares e meio ambiente não foram mencionadas.

Ao ensinar, os docentes expressam o saber que adquiriram na sua formação acadêmica e nas experiências profissionais. No processo pedagógico, os docentes gerenciam as normas antecedentes, os valores, os conhecimen- 
tos e as condições concretas disponíveis em cada situação e cenário de prática. Conhecimentos, percepções culturais e sociais interferem na implementação de práticas seguras. O docente necessita de bases científicas, e na enfermagem é primordial associar teoria e prática. No entanto, as condições concretas de infraestrutura e materiais disponíveis são fortemente determinantes na possibilidade de ensinar e realizar cuidados seguros.

Nesse contexto, as escolas profissionalizantes, responsáveis pela formação de um dos maiores contingentes de profissionais de enfermagem no país, desempenham um papel fundamental na sensibilização para o agir seguro, contribuindo para o fortalecimento da profissão e uma assistência de saúde mais qualificada.

A pesquisa mostrou que os docentes compartilham o entendimento da importância de se adotarem práticas laborais seguras e de que o ensino influencia as ações dos futuros profissionais.

\section{Colaboradores}

Gerusa Ribeiro redigiu o presente artigo, que resultou da dissertação Enfermeira(o), docente na atividade prática supervisionada: a biossegurança prescrita, de sua autoria. Denise Elvira Pires de Pires participou como orientadora e contribuiu no desenvolvimento do texto. Rita de Cássia Flôr realizou a revisão do artigo. 
Resumen El respeto a las normas de bioseguridad es fundamental para la realización de cuidados seguros, y la enseñanza en la formación profesional en salud desempeña un papel fundamental en este proceso. Este artículo es el resultado de una investigación exploratoria y descriptiva, de enfoque cualitativo, con el objetivo de identificar las concepciones de bioseguridad de docentes de la enseñanza técnica de enfermería que actúan en instituciones vinculadas a la Red Federal de Educación Profesional y Tecnológica de un estado del Sur de Brasil. Los datos se recolectaron por medio de entrevistas con el universo de los enfermeros docentes de dos instituciones que realizaron actividades supervisadas de pasantía durante el período de un mes, en 2012. Los resultados mostraron tres visiones de bioseguridad: como sinónimo de equipos de protección personal; como protección de los involucrados en el trabajo; y como seguridad de la vida. Se observó además que el docente reproduce lo que aprendió en la escuela y toma decisiones bajo la influencia de los escenarios de su práctica. Se concluyó que los docentes entienden la importancia de adoptar prácticas laborales seguras y que la enseñanza influye en las acciones de los futuros profesionales; no obstante, la concepción de defensa de la vida fue minoritaria.

Palabras clave exposición a agentes biológicos; bioseguridad; enfermería; educación técnica en enfermería; salud del trabajador.

\section{Notas}

${ }^{1}$ Instituto Federal de Educação, Ciência e Tecnologia de Santa Catarina, Florianópolis, Santa Catarina, Brasil.

<gerusa@ifsc.edu.br>

Correspondência: Rua Presidente Nereu Ramos, 1.055, apto. 1.301, CEP 88101-410, Campinas, São José, Santa Catarina, Brasil.

2 Universidade Federal de Santa Catarina, Programa de Pós-Graduação em Enfermagem, Florianópolis, Santa Catarina, Brasil.

<piresdp@yahoo.com>

3 Instituto Federal de Educação, Ciência e Tecnologia de Santa Catarina, Florianópolis, Santa Catarina, Brasil.

$<$ flor@ifsc.edu.br>

4 Este artigo é produto da dissertação de mestrado intitulada Enfermeira(o), docente na atividade prática supervisionada: a biossegurança prescrita, de autoria da primeira autora, apresentada ao Programa de Pós-Graduação em Enfermagem da UFSC. 


\section{Referências}

ANDRADE, Andréia C.; SANNA, Maria C. Ensino de biossegurança na graduação em enfermagem: uma revisão da literatura. Revista Brasileira de Enfermagem, Brasília, v. 60, n. 5, p. 569-572, set./out. 2007.

BARDIN, Laurence. Análise de conteúdo. Lisboa: Edições 70, 2010.

BRASIL. Ministério do Trabalho e Emprego. Portaria n. 3.214, de 8 junho de 1978. Aprova a norma regulamentadora NR 6. Disponível em: <http://portal.mte.gov.br/data/files/ 8A7C812D36A2800001388130953C1EFB/ NR-06\%20(atualizada)\%202011.pdf>. Acesso em: 2 out. 2012.

BRASIL. Ministério da Saúde. Portaria n. 1.683/GM, 28 de agosto de 2003. Diário Oficial da União, Brasília, DF, 28 ago. 2003. Disponível em: <ftp://ftp.saude.sp.gov.br/ ftpsessp/bibliote/informe_eletronico/2011/ iels.ago.11/Iels151/U_PT-MS-GM-1914_ 110811.pdf $>$. Acesso em: 10 ago. 2015.

BRASIL. Lei n. 2.604, de 17 de setembro de 1955. Regula o exercício da Enfermagem Profissional. Diário Oficial da União, Brasília, DF, 21 set. 1955. Disponível em: $<$ www2.camara.leg.br/legin/fed/lei/19501959/lei-2604-17-setembro-1955-361190publicacaooriginal-1-pl.html>. Acesso em: 10 ago. 2015.

BRASIL. Lei n. 7.498, de 26 de junho de 1986. Dispõe sobre a regulamentação do exercício da Enfermagem e dá outras providências. Diário Oficial da União, Brasília, DF, 26 jun. 1986. Disponível em: <www. planalto.gov.br/ccivil_03/leis/17498.htm>. Acesso em: 10 ago. 2015.

BRASIL. Lei n. 11.105, de 24 de março de 2005. Regulamenta os incisos II, IV e V do $\S 1^{\circ}$ do art. 225 da Constituição Federal, estabelece normas de segurança e mecanismos de fiscalização de atividades que envolvam organismos geneticamente modificados (OGM) e seus derivados, cria o Conselho Nacional de Biossegurança (CNBS), reestrutura a Comissão Técnica Nacional de Biossegurança (CTNBio), dispõe sobre a Política Nacional de Biossegurança (PNB), revoga a lei n. 8.974, de 5 de janeiro de 1995, e a medida provisória n. 2.191-9, de 23 de agosto de 2001, e os arts. $5^{\circ}, 6^{\circ}, 7^{\circ}, 8^{\circ}, 9^{\circ}, 10$ e 16 da lei n. 10.814 , de 15 de dezembro de 2003, e dá outras providências. Diário Oficial da União, Brasília, 24 mar. 2005a. Disponível em: $<$ www.planalto.gov.br/ccivil_03/_ato20042006/2005/lei/111105.htm>. Acesso em: 10 ago. 2015.

BRASIL. Resolução do Conselho Nacional de Educação/Câmara de Educação Básica (CNE/CEB) n. 1/2005. Atualiza as Diretrizes Curriculares Nacionais definidas pelo Conselho Nacional de Educação para o Ensino Médio e para a Educação Profissional Técnica de nível médio às disposições do decreto n. 5.154/2004. Brasília, fev. 2005b. Disponível em: <http://portal.mec.gov.br/ cne/arquivos/pdf/rceb001_05.pdf > . Acesso em: 10 ago. 2015.

BRASIL. Ministério do Trabalho e Emprego. Portaria n. 485, de 11 novembro de 2005c. Aprova a norma regulamentadora NR 32. Disponível em: <http://portal.mte.gov.br/ data/files/8A7C812D36A280000138812 EAFCE 19E 1/NR-32\% 20(atualizada \% 202011).pdf>. Acesso em: 2 out. 2012.

BRASIL. Lei n. 8.974, de 5 de janeiro de 1995. Regulamenta os incisos II e V do $\S 1^{\circ}$ do art. 225 da Constituição Federal, estabelece normas para o uso das técnicas de engenharia genética e liberação no meio ambiente de organismos geneticamente modificados, autoriza o Poder Executivo a criar, no âmbito da Presidência da República, a Comissão Técnica Nacional de Biossegurança, e dá outras providências. Diário Oficial da União, Brasília, DF, 5 jan. 1995. Disponível em: <www.planalto.gov.br/ccivil_ 03/LEIS/L8974.htm>. Acesso em: 10 ago. 2015. 
BRASIL. Ministério da Educação. Instituto Federal de Educação, Ciência e Tecnologia: concepções e diretrizes. Brasília: Ministério da Educação, 2008. Disponível em: <http:// portal.mec.gov.br/index.php?option $=\mathrm{com}_{-}$ docman \& view = download \&alias $=6691-$ if-concepcaoediretrizes\&category_slug= setembro-2008-pdf\&Itemid=30192>. Acesso em: 13 set. 2015 .

BRASIL. Ministério da Educação. Estabelece as diretrizes e bases da educação nacional. Brasília: Ministério da Educação, 1996. Disponível em: <www.planalto.gov.br/ccivil_03/ LEIS/L9394.htm>. Acesso em: 10 ago. 2015.

BRASIL. Portaria da Secretaria de Inspeção do Trabalho (SIT) n. 194, de 7 de dezembro de 2010. Altera a norma regulamentadora n. 6 (equipamentos de proteção individual EPI). Diário Oficial da União, Brasília, DF, 8 de dezembro, 2010. Disponível em: <www. udop.com.br/download/legislacao/trabalhista/ institucional_site_juridico/port_194_ competencia_cipa.pdf>. Acesso em: 10 ago. 2015.

BRASIL. Portaria n. 343, de 19 de fevereiro de 2002. Institui a Comissão de Biossegurança em Saúde. Diário Oficial da União, Brasília, DF, 21 de fevereiro, 2002. Disponível em: <http://cibio.ufsc.br/files/2009/09/ portaria_343_MS.pdf $>$. Acesso em: 10 ago. 2015.

CAMPOS, Gastão W. S. Subjetividade e administração de pessoal: considerações sobre modos de gerenciar o trabalho em equipes de saúde. In: MERHY, Emerson E.; ONOCKO, Rosana. Praxis en salud: um desafio para lo público. São Paulo: Hucitec, 1997. p. 229-266.

CANALLI, Rafaela T. C.; MORIYA, Tokico M.; HAYASHIDA, Miyeko. Prevenção de acidentes com material biológico entre estudantes de enfermagem. Revista de Enfermagem, Rio de Janeiro, v. 19, n. 1, p. 100-106, jan./mar. 2011.

CARDOSO, Telma. A. O. et al. Memories of Biosafety in Brazil: lessons to be learned. Journal of the American Biological Safety Association Applied Biosafety, Mundelein, v. 10, n. 3, p. 160-168, 2005.
CENTERS FOR DISEASE CONTROL AND PREVENTION (CDC). Biosafety in microbiological and biomedical laboratories. 5. ed. Washington, D.C.: U.S. Government Prenting Office, 2009. Disponível em: <www. cdc.gov/biosafety/publications/bmbl5/ BMBL.pdf>. Acesso em: 3 out. 2012.

COREN-SC (Conselho Regional de Enfermagem de Santa Catarina). Normas regulamentadoras (NR) do Ministério do Trabalho e Emprego relativas à saúde e segurança do trabalhador de saúde. In: SILVA, Rosilda V. et al. (org.). Série Cadernos Enfermagem. Flo-rianópolis: Letra Editorial, 2011. v. 2. p. 132 .

COREN-SC (Conselho Regional de Enfermagem de Santa Catarina). Estatísticas de profissionais $497^{a}$ ROP. 14 de setembro de 2012. Disponível em: <www.corensc.gov.br/estatisticas>. Acesso em: 10 set. 2014.

COREN-RS (Conselho Regional de Enfermagem do Rio Grande do Sul). Número de inscritos ativos por categoria profissional. 2014. Disponível em: <www.portalcoren-rs.gov.br/ index.php? categoria $=$ servicos \& pagina $=$ estatisticas>. Acesso em: 10 set. 2014.

COSTA, Marco A. F. Biossegurança e qualidade: uma necessidade de integração. Biotecnologia: Ciência \& Desenvolvimento, Natal, v. 4, n. 1, p. 32-33, 1998.

COSTA, Marco A. F. Construção do conhecimento em saúde: o ensino de biossegurança em cursos de nível médio na Fundação Oswaldo Cruz. Tese (Doutorado em Enfermagem) - Instituto Oswaldo Cruz, Fundação Oswaldo Cruz, Rio de Janeiro, 2005.

COSTA, Marco A. F.; COSTA, Maria F. B. Biossegurança de OGM: saúde humana e ambiental. Rio de Janeiro: Papel e Virtual, 2003.

CosTA, Marco A. F.; CostA, Maria F. B. Educação em biossegurança: contribuições pedagógicas para a formação profissional em saúde. Ciência \& Saúde Coletiva, Rio de Janeiro, v. 15, n. 2, supl., p. 1.741-1.750, 2010 . 
CUSTÓDIO, Carolina S.; SANTOS, Renata C. Equipamentos de risco biológico. In: SILVA, José. V.; DUARTE, Suélen R. (org.). Biossegurança no contexto da saúde. São Paulo: Iátria, 2013. p. 33-44.

KREMPEL, Cristina M. Regulação das profissões de enfermagem: desafios contemporâneos na Ibero-América. Conferência. Congresso Brasileiro dos Conselhos de Enfermagem, 15. Ceará, 1-26 ago. 2012. Disponível em: <http://apps.cofen.gov.br/cbcenf/ sistemainscricoes/anais.php? evt $=10 \& \mathrm{sec}=$ $69 \&$ niv =5 > . Acesso em 10 ago. 2015.

MARX, Karl. O capital: crítica da economia política. Livro 1: O processo de produção do capital. 13. ed. Rio de Janeiro: Bertrand, 1989.

ODA, Leila M.; SANTOS, Bruna C. Memórias da biossegurança e biosseguridade: de Asilomar à biologia sintética. In: HIRATA, Maria H. Manual de biossegurança. 2. ed. São Paulo: Manole, 2012. p. 295-305.

PEREIRA, Maria E. C. et al. Reflexões sobre conceitos estruturantes em biossegurança: contribuições para o ensino de ciências. Ciências \& Cognição, Rio de Janeiro, v. 14, n. 1, p. 296-303, mar. 2009.

PIRES, Denise E. P. A enfermagem enquanto disciplina, profissão e trabalho. Revista Brasileira de Enfermagem, Brasília, v. 62, n. 5, p. 739-744, set./out. 2009.

PIRES, Denise E. P.; LORENZETTI, Jorge; GELBCKE, Francine L. Enfermagem: condições de trabalho para um fazer responsável. In: CONGRESSO BRASILEIRO DE ENFERMAGEM - ORGANIZAÇÃO E VISIBILIDADE PROFISSIONAL, 62., Florianópolis, 2010. Anais do Congresso Brasileiro de Enfermagem: organização e visibilidade profissional. Brasília: Associação Brasileira de Enfermagem (Aben), 2010.

SCHWARTZ, Yves; DURRIVE, Louis. Trabalho e ergologia. In: SCHWARTZ, Yves; DURRIVE, Louis (org.). Trabalho \& Ergologia: conversas sobre a atividade humana. 2. ed. Niterói: EdUFF, 2010. p. 25-36.
SIEGEL, Jane D.; RHINEHART, Emily; CHIARELLO, Linda M. J.; The Healthcare Infection Control Practices Advisory Committee. Guideline for isolation precautions: preventing transmission of infectious agents in healthcare settings, 2007. Disponível em: <www.cdc.gov/hicpac/pdf/isolation/ Isolation2007.pdf>. Acesso em: 10 ago. 2015.

SILVA, Aline D. R. L.; MASTROENI, Marco F. Biossegurança: o conhecimento dos formandos da área da saúde. Revista Baiana de Saúde Pública, Salvador, v. 33, n. 3, p. 476-487, jul./set. 2009.

SOUZA, Adenícia C. S. et al. Conhecimento dos graduandos de enfermagem sobre equipamentos de proteção individual: a contribuição das instituições formadoras. Revista Eletrônica de Enfermagem, Goiânia, v. 10, n. 2, p. 428-437, 2008. Disponível em: <www.fen. ufg.br/fen_revista/v10/n2/pdf/v10n2a14. pdf>. Acesso em 10 ago. 2015.

SOUZA, Alvaro F. L. et al. O ensino da biossegurança em saúde por docentes da graduação em enfermagem. Revista Interdisciplinar, Centro Universitário Uninovafapi, Teresina, v. 7, n.1, p. 85-92, jan./fev./mar. 2014.

TEIXEIRA, Pedro; VALLE, Silvio. Biossegurança: uma abordagem multidisciplinar. Rio de Janeiro: Editora Fiocruz, 2010.

WALDOW, Vera R. Momento de cuidar: momento de reflexão na ação. Revista Brasileira de Enfermagem, Brasília, v. 62, n. 1, p. 140-145, jan./fev. 2009.

WONG, Brenda J. Basic biosafety principles. EH\&S Academy, UCSD Biosafety Officer, 2009. Disponível em: <www.ehs.ucr.edu/ ehsacademy/presentations/biosafety.ppt $>$. Acesso em: 10 set. 2012.

Recebido em 20/02/2014

Aprovado em 20/11/2014 